\title{
Algumas Notas para a Reconstrução do Princípio da Legalidade
}

\author{
Eros Roberto Grau \\ Professor Adjunto do Departamento de \\ Direito Econômico-Financeiro da Faculdade \\ de Direito da Universidade de São Paulo
}

01. - O princípio da legalidade tem sido visualizado, pela maior parte da doutrina, como expressivo de uma regra de limite para a atuação estatal. Penso deva essa concepção ser objeto de revisão, o que conduzirá à própria reconstrução do princípio.

Esta perspectiva, que adoto, pode eventualmente sujeitar os que a ela se filiem a críticas alinhadas no sentido de apontá-los como detratores de princípio. A postulação de tais críticas, contudo, não é justa nem adequada.

O que se pretende, desde a perspectiva a que me refiro, é, no fundo, recuperar as virtualidades do princípio, de modo que passe ele a expressar garantia material - e não apenas formal - para os indivíduos e a sociedade.

É evidente que a exposição de tal perspectiva transita pela consideração de inúmeros pontos e aspectos, que não cabem nos lindes destas pequenas notas que passo a enunciar, sublinhando o caráter mítico do princípio. Compõe-se elas, no entanto, entre as emergentes desde uma - e não a única, evidentemente - das vertentes para a análise do princípio.

Tratando-se meramente de notas, não ficarei constrangido por dispô-las de modo sintético, cuidando tão-somente de preservar o adequado encadeamento que as relaciona.

02. - Em sua origem, o princípio consubstancia um dado fundamental para a construção da noção de Estado de Direito ${ }^{1}$, esta enquanto noção meramente formal. E, desde aî, opera-se como que uma causação circular entre ambos, de modo que a legalidade, na acepção liberal, passa a cumprir a função de garantia dos particulares contra a atuação estatal - o que implica no impedimento de que o Executivo, por ato seu, possa estabelecer restrições à liberdade e à propriedade dos indivíduos, ou seja, em defesa dos indivíduos contra o Poder Público ${ }^{2}$. O princípio é então visualizado em termos estri-

1. Como observa FRANCESCO GALGANO (Il Diritto Privato fra Codice e Costituzione, Zanichelli, Bologna, 1979, pág. 39), o conceito de Estado de Direito exprime, em relação ao burguês singular, aquela mesma exigência - de um limite à ação pública, para salvaguarda à iniciativa privada - que o conceito de Estado Liberal exprime em relação à burguesia no seu todo.

2. Vide CELSO ANTONIO BANDFIRA DE MELLO, Ato Administrativo e Direitos dos Administrados, Editora Revista dos Tribunais, São Paulo, 1981, pág. 83 e ss. Note-se, 
tamente formais, como corolário da separação dos poderes, importando exclusivamente na aposição de um limite à atuação do Estado.

$\mathrm{Na}$ falaciosa crença de que a teoria da separação dos poderes deveu-se, no seu lento processar, exclusivamente à necessidade de preservar as liberdades, à legalidade atribui-se o desempenho de duplo de papel: o de instrumento ancilar dessa preservação e o de substituto do princípio da legitimidade.

03. - Disso resultam algumas conseqüências, que me parece estejam a reclamar análise bem detida.

A primeira, na institucionalização - com a consagração do princípio da legalidade - da cisão entre o Estado moderno e a sociedade civil, que a noção de liberdade pública, tida só como noção formal, evidencia.

A segunda, no necessário - para que a consistência do princípio possa ser mantida - escamoteamento da evidência de que as liberdades modernas são liberdades jurídicas, ou seja, definidas pelo Direito, laicizadas ${ }^{3}$. E, no desdobramento deste escamoteamento, na fuga à compreensão de que a legalidade pode prestar-se, inúmeras e incontidas vezes, a servir como instrumento de opressão e opóbrio.

Daí uma conclusão que me parece bem nitida: a da insuficiência da concepção da legalidade em termos estritamente formais para prover a garantia das liberdades.

04. - A transformação (na verdade, involução) pela qual passa o princípio, desde a sua enunciação inicial, é desenhada por MASSIMO SEVERO GIANNINI ${ }^{4}$.

Originariamente implicava em que todo elemento de um ato da Administração deveria estar expressamente previsto como elemento de alguma hipótese normativa, devendo a norma fixar poderes, direitos, deveres, etc., modos e seqüência dos procedimentos, atos e efeitos em cada um dos seus componentes e requisitos de cada ato - do que resultava a concepção do Poder Executivo como administração e da Administração como execução.

Modernamente o princípio assume significado diverso, na expressão de GIANNINI "mais limitado num certo aspecto, porém mais afinado em outro": atém-se à atividade administrativa erquanto esta se exprime em atos que possuem conteúdo autoritário.

Daí porque mudou o valor do princípio, que deixa de ser - se é que não foi apenas teoricamente - regra de conteúdo da atividade administrativa, para sobreviver como regra do seu limite, inserida na dialética da autoridade e da liberdade.

contudo, que esta visão, estrita, da legalidade, resulta superada pelo próprio CELSO ANTONIO em seu mais recente Controle Judicial dos Atos Administrativos, in RDP $65 / 27$ e ss.

3. Vide meu Autorização pana o exercicio de iniciativa económica Agencias de Turismo, in Revista de Direito Mercantil, no 49, pág. 23.

4. Diritto Amministrativo, volume primo, Giuffrè Editore, Milano, 1970, págs. 81/83. 
Por isso que - como expõe GIANNINI - o princípio respeita aos procedimentos administrativos não já em si, mas tão-somente enquanto a eles seja correlata uma situação subjetiva do particular, sobre a qual tenha incidência um efeito de extinção ou limitação. Por isso, ainda, é que, nos casos em que a atividade administrativa não expressa aquela dialética, o princípio não é aplicado - tal como no caso da atividade de programação do Estado e de outros entes públicos, que não se exprimem em atos autoritários.

Conseqüência disso é a de que - repita-se - o princípio, atualmente, é concebido apenas como regra de limite para a ação da Administração, não operando, como observa GALGANO ${ }^{5}$, qualquer garantia de fins públicos, já que visa tão-somente à proteção do interesse privado.

Inescondíveis, destarte, nesta concepção do princípio da legalidade, as marcas profundas do pensamento liberal, que ideologicamente a estruturam.

$\mathrm{Na}$ consagração da legalidade como critério meramente formal, pois, a ereção de pilastra hábil a dar justificativa ao Direito posto, independentemente de qualquer valoração a propósito do seu conteúdo. Já não compete ao estudioso do Direito, desde então, a avaliação da justiça do poder - tal como exercido sob o manto da legalidade ou da norma. Incumbe-lhe, pelo contrário, colocar o seu saber a serviço do objetivo de reduzir o quanto mais se possa a ação estatal e, na impossibilidade disso, ao sabor de valores bem definidos.

A política da legalidade, desta sorte, conduz à neutralidade axiológica do Direito e à anulação do direito de resistência contra o Direito injusto. O que importa, desde a perspectiva instalada na consagração do princípio, tal como atualmente concebido, é que as normas jurídicas sejam rigorosamente cumpridas. Por consequiência, a legalidade assume o caráter de dogma.

Em um passo seguinte, a legalidade - tal como a noção de Estado de Direito - passa a funcionar como estereótipo e, de imediato, como mito do liberalismo burguês.

Alcançado este momento de minha exposição, posso - e devo nela prosseguir por uma senda específica, na consideração da legalidade como expressão ideológica ou mítica ${ }^{6}$.

06. - Podemos aludir à ideologia como estrutura que se refere ao modo pelo qual os homens vivem o todo de suas relações com o mundo ${ }^{7}$ Para que essas relações se traduzam em ações - no sen-

5. Ob. cit. pág. 39.

6. "O mito é uma forma específica de manifestação do ideológico no plano do discurso" (cf. LUfS ALBERTO WARAT, Mitos e Teorias na Interpretação da Lei, Editora Síntese, Porto Alegre, 1979, pág. 127).

7. Foi de extrema valia, para a exposição que segue, minha freqüente troca de idéias e debate informal com PAULO AMELIO DO NASCIMENTO SILVA, professor de linguística da Universidade Estadual do Rio de Janeiro, bem assim a leitura de sua tese de livre-docência, Referência e Significasãa, Rio, 1976, ed. mimeografađa. 
tido, aí, da palavra grega dianóia - devem ser mediatizadas pela linguagem.

A ideologia, mediatrizada pela linguagem, é uma fonte de produção de sentido. Não, porém, na acepção comum de sentido, mas como valor de referência.

A ideologia não produz significados que valham por si mesmos, mas valores-verdade que se auto-referenciam, ou seja valores referenciais que são verdadeiros ou falsos conforme sua relação com as pautas ideológicas que compõem a sua instância de enunciação, seja como conformidade, seja como contraste. O valor do verdadeiro ou falso, assim, no âmbito da ideologia, é arbitrário, formal - não ontológico, conteudístico. Por isso mesmo a ideologia é referencial ou monossignificativa, desconhecendo no real, por não reconhecer, tudo quanto seja com ela incompativel.

Nisto é que o discurso ideológico e o discurso mítico se aproximam: ambos instauram um horizonte objetivo para os comportamentos e atitudes do homem, embora o primeiro se insira e viva da história e o segundo se desenvolva em uma realidade não-histórica, atemporal e sem espaço. Note-se que o mito aparenta ser uma revelação do que foi e permanece sendo.

Não obstante, o mito funciona como recurso lingüístico no discurso ideológico de quem tem condições de, através dele, exercer dominação.

07. - Os mitos são descritos como formas de fé popular que não nasceram da reflexão racional do povo, mas de sentimentos pré-racionais, emotivos.

Desvendados, porém, desnuda-se a racionalidade deles em quem os inventa, o que evidencia não serem senão uma manifestação cultural. O mito, em verdade, não passa de uma invenção, consciente ou inconsciente, do homem ou de um grupo de homens, cuja finalidade é a de instauração de uma (nova) ordem.

Penso possamos sustentar, assim, que o momento da "desmitização da cultura", no iluminismo racionalista, sustentado sobre a afirmação da obscuridade dos mitos, característica - conforme se alegou - das Idades Antiga e Média, não consubstanciou senão um momento de substituição de mitos. Mitos irracionais ou inconscientes são então substituídos por outros, mitos também, porém definidamente conscientes e racionais nos que os inventam.

Invenção do homem (ou de um grupo de homens), os mitos modernos - não o mito para o homem, como o mito drummondiano de "fulana", mas o mito para o povo ou para a sociedade civil - são como expressões exotéricas, a serem "consumidas" pela sociedade. São impostos à sociedade, assim, funcionando como instrumentos lingüísticos de dominação, que tanto mais prosperam quanto mais são acreditados ${ }^{8}$.

8. De WARAT (ob. cit., 127) também a observação de que consubstanciam estereotipação semiológica da ideologia e instrumento de reprodução de formas sociais hegemônicas. 
08. - Tanto quanto o discurso ideológico, o discurso mítico é exclusivamente referencial.

A proposição "Pégaso é um cavalo alado", em si mesma, não é logicamente falsa nem verdadeira. Vale dizer: não tem significado, mas valor de referência verdadeiro quando na instância de enunciação da mitologia, falso quando em qualquer outra instância de enunciação.

Assim, assumindo a legalidade o caráter de mito, a proposição "a democracia só conhece a legalidade, não a legitimidade" " ${ }^{\circ}$ nạ instância de enunciação jurídica, não é, em si mesma, verdadeira nem falsa. Não tem significado, mas tão só valor de referência: é tomada como verdadeira naquela instância.

Eis então a legalidade erigida em mito do liberalismo burguês, sob o qual repousa a afirmação, extraída à falaciosa leitura de MAX WEBER ${ }^{10}$, de que ela (legalidade), enquanto legitimidade racional, foi e permanece sendo. A legalidade, destarte, enquanto noção que substitui - execrando-a - a de legitimidade, opera a exclusão, do âmbito dos debates jurídicos, de qualquer consideração a respeito desta última.

O mito da legalidade, assim, retém o estudioso do Direito em um universo de "dever ser" axiologicamente neutralizado. No discurso jurídico ${ }^{11}$, esvazia o real e pacifica a consciência dos juristas, inclusive dos juízes, fazendo com que todos se conformem com a situação que lhes foi imposta por quem detém o poder de criar o Direito.

09. - Em vista disso cumpre, a cogitarmos da reconstrução do princípio da legalidade, preliminarmente tratarmos de desmitificá-lo. Esse exercício, contudo, importa desmitificação também da noção de Estado de Direito.

Este - Estado de Direito - não pode ser visto como um sistema fechado e fixo, com valor em si próprio, mas como conceito temporalmente condicionado, aberto ${ }^{12}$. Há que substituir a noção de Estado de Direito Formal pela de Estado de Direito Material, sustentado sobre a concreção do princípio democrático e de uma ordem jurídica legí-

9. Nesta estrutura, a proposição é formulada por ÁLVARO D'ORS (Legitimidad, Revista Chilena de Derecho, 1981, vol. 8, pág. 43).

10. WEBER (Economia y Sociedade, vol. I, trad de JOSÉ MEDINA ECHAVERRIA e outros, Fondo de Cultura Economica, México, 1969), em realidade, embora superponha as idéias de legitimidade racional e de legitimidade (pág. 30), em trecho posterior de sua obra (pág. 640) afirma: "Direito Natural é o conjunto de normas vigentes preeminentemente frente ao direito positivo e independentemente dele, que não devem sua dignidade a um estabelecimento arbitrário, mas, pelo contrário, legitimarn a força obrigatória deste. Isto é, o conjunto de normas que valem não em virtude de porvir de um legislador legitimo, mas em virtude de qualidades puramente imanentes: forma específica e unica conseqüente da legitimidade que fica quando decaem a revelação religiosa e a santidade hereditária da tradição. O direito natural é por isso a forma específica da legitimidade do ordenamento jurídico revolucionariamente' criado" (grifo no original). Nisso, evidentemente, a alusão de WEBER a uma legitimidade que não se identifica, estando acima dela, com a legalidade.

11. A afirmação é de WARAT, ob. cit. pág. 129.

12. Vide JOS JOAQUIM GOMES CANOTILHO, Direito Constitucional, vol. II, Almedina, Coimbra, 191, pág. 14. 
tima. Por isso que a noção de Estado de Direito não consubstancia um fim em si mesmo, mas o meio virtual para a realização da democracia e a construção de uma ordem jurídica legítima.

Pois bem: neste contexto, do Estado de Direito Material, é que se pode - e deve - operar a desmitificação do princípio da legalidade.

Por certo que a sua validade é inquestionável, mesmo enquanto garantidora da forma jurídica, inimiga declarada da arbitrariedade e irmã gêmea da liberdade, na inesquecível dicção de Von IHERING ${ }^{13}$. Imperioso é que não se faça uso da legalidade como mecanismo de escamoteamento do conteúdo da noção de Estado de Direito Material.

10. - De outra parte, a desmitificação da legalidade há também de nos levar, na sua conseqüente reconstrução, à instauração dela não como mera pauta de limite da atuação estatal, mas - tal como afirmei inicialmente - como regra de predeterminação do conteúdo dessa atuação.

$\mathrm{Na}$ tarefa a ser desenvolvida tendo em vista tal reconstrução, muito do que temos a fazer não apresenta sabor de inovação, antes, pelo contrário, consubstanciando mera recuperação de noções já consagradas no nível teórico, mas que, estranhamente, jamais foram levadas plenamente a concreção. Assim, v.g., com a recusa de acatamento à vinculação negativa da Administração pela lei. Esta - a doutrina do negative Bindung - é pacificamente substituída, no pensamento jurídico moderno, pela de positive Bindung, nos termos da qual a lei é pressuposto do atuar da Administração ${ }^{14}$.

De outra parte, nele visualizando a predeterminação do conteúdo da Administração, há de o princípio ser referido, como enfatiza EDUARDO GARCIA DE ENTERRIA ${ }^{15}$, não há um tipo de norma específica e determinada, mas ao ordenamento todo, ao que HAURIOU chamou "bloco da legalidade" De onde, por conseqüência, a imperiosidade de concebermô-lo como alcançando a Administração também pelos efeitos contidos na fórmula "legem patere quam fecisti".

11. - As breves observações assim produzidas podem, segundo penso, ao lado de inúmeras outras, a serem colhidas desde outras perspectiva, efetivamente subsidiar a revisão construtiva do princípio, que se reclama. Que não se prestem, no entanto, a justificar senão o repúdio que se confira à concepção meramente formal da legalidade. A recuperação desta, para que subsista consagrada em termos materiais, tenho-a como indispensável à realização das vocações autênticas do Direito.

13. O Espirito do Direito Romano, vol. III, trad. de Rafael Benalon, Alba Editora, Rio de Janeiro, 1943, pág. 115.

14. Vide, a propósito, a exposição de EDUARDO GARCIA DE ENTERRIA y TOMASRAMON FERNANDEZ (Curso de Derecho Administrativo, vol. I, cuarta edicion, Civitas, Madrid, 1983, pág. 413 e ss.).

15. Ob. cit., pág. 413. 